\title{
GROUPWARE INTEGRATION IN VIRTUAL LEARNING TEAMS
}

\author{
A qualitative analysis based on the TAM-model
}

\author{
Pernille Bjørn and Ada Scupola \\ Roskilde University, Denmark
}

\begin{abstract}
In this paper we apply Davis' Technology Acceptance Model (TAM) in a qualitative fashion to analyze and interpret the chronological sequence of events leading to the acceptance of the Groupware technology, BSCW, in a virtual learning team. The research question investigated is: What are the factors influencing the integration process of Groupware technology in virtual learning teams in part-time adult education? The data were gathered through an in-depth qualitative action research study of one virtual learning team doing problem-oriented project work within a master education program. We find that one important factor influencing the integration process of Groupware is: How the technology provides support for social perspective awareness. In the case investigated the technology BSCW supported social awareness, which influenced both the ease-of-use and the perceived-usefulness of the Groupware technology, thus being an important condition that influenced the positive outcome of the integration process.
\end{abstract}

Key words: Technology Acceptance Model, Social Awareness, Groupware, Master Education, Virtual Team, Learning, BSCW, CSCL

\section{INTRODUCTION}

Problem-oriented learning and university teaching based on a pedagogy whereby students collaborate in teams are a central part of newer educational research (Olesen and Jensen, 1999). At the same time there is a demand that it should be possible to take an education anywhere at any time. Close collaboration in distance setting could be a contradiction in terms, however new technology such as Groupware gives us the opportunity to do both. Geographical distributed project teams need technology support for 
collaborative activities. We define a virtual team as a team comprising geographically distributed participants who mainly mediate their collaborative activities through technology. The team collaboration can be supported by e-mail correspondence, phone meetings or by using more advanced Groupware technologies such as the BSCW (Basic Support for Cooperative Work). The foundation of these kinds of technologies is advanced file-management systems based on web-technologies (Bentley et al., 1997). We however need new innovations in this field to insure success with Groupware technologies.

Current research on Groupware states that appropriate support for the integration, implementation and continued use of the technology is crucial for success (Karsten, 1999; Orlikowski, 1992; Grudin, 1994 and Majchrzah et al., 2000). Drawing on these findings we conducted an action research project, where we intervened to facilitate a virtual learning team in integrating Groupware. Our action research approach was to support the integration by assisting the team to develop and implement coordination mechanisms (Schmidt and Simone, 1996). Here we describe how the virtual learning team went from using e-mail and phone to mediate their collaboration by integrating Groupware to support the distributed practice.

When analyzing the data we needed a model to examine why the integration succeed. We used Davis' Technology Acceptance Model (Davis, 1989) - the TAM-model - as a 'lens' or framework to describe and analyze the different factors that influenced the integration process at different periods of time. We chose to use the TAM-model for two main reasons. First the TAM-model is the most well-known, rigorously validated empirically and widely accepted model for examining technology acceptance (Legris et al., 2003; Adams et al., 1992; Davis, 1989; Davis et al., 1989), and secondly because we found that the model constructs Ease-of-use, Perceivedusefulness, Intentional-use and Actual-use provided a framework, which was useful when analyzing the integration process.

Groupware support for Problem Oriented Project work in distributed part-time education has been investigated in a range of studies (e.g. Dirckinck-Holmfelt and Sorensen, 1999; Cheesman and Heilesen, 1999; Bjørn, 2003). However none of these studies has used the TAM-model to investigate the Groupware integration process. This paper does so by reflecting and analyzing the integration of Groupware technology in a virtual learning team by using the TAM-model in a qualitative and interpretative way. The overall research question investigated is: What are the factors influencing the integration process of Groupware technology in virtual learning teams in part-time adult education?

We found that besides the importance of coordination mechanisms another aspect of Groupware technology influenced the integration in a 
positive way: social perspective awareness. We define social perspective awareness as background information on belief and knowledge of team members, similar to the information one can gather when working around in the physical office. Groupware technology affected the social setting in the virtual team by providing support for an unarticulated need in the team for social perspective awareness. So besides supporting the need for coordination and document handling, which we expected, the Groupware technology also supported the team's need for perspective awareness. This factor influenced the integration of this technology in a positive way. We use the TAM-model to illustrate this point while showing that social perspective awareness influences both the construct Ease-of-use and the construct Perceived-usefulness in the model.

The paper is structured as follows. In the next section, the TAM model and its application in a variety of contexts are presented. Then, the concept of social perspective awareness and its relevance to virtual teams is discussed. Following this, the research setting, research method and data analysis is presented. In the empirical part of the paper we analyze the integration of Groupware technology over four key checkpoints, followed by a discussion of the research results. Finally, the conclusions, limitations and implications of the study for further research using the TAM model in integration of Groupware in virtual learning teams are discussed.

\section{THE CONCEPTUAL BASE}

\subsection{Technology Acceptance Model (TAM)}

Davis (1989) synthesized the findings of a range of diverse research streams to propose the Technology Acceptance Model (TAM), which identifies a number of constructs relevant to technology acceptance (First publish in Davis' dissertation in 1986). These constructs fall into two broad categories, ease of use (EoU) and perceived usefulness (PU). Davis suggests a chain of causality between these categories: greater EoU leads to higher $\mathrm{PU}$, which in turn leads to more usage of technology (see Fig. 1).

In the original TAM-model two more constructs were present in addition to those in fig. 1: External variables and Attitude. The external variables influenced both EoU and PU, while Attitude was influenced by both EoU and PU affecting the construct Intentional-use. We have chosen not to include the External-variables and Attitude in our model, drawing on the research of Legris et al. (2003) and Gefen et al. (2003). In fact, Legris et al. (2003) found that in most cases researchers have mainly considered EoU and PU and their effects on Intentional-use. 


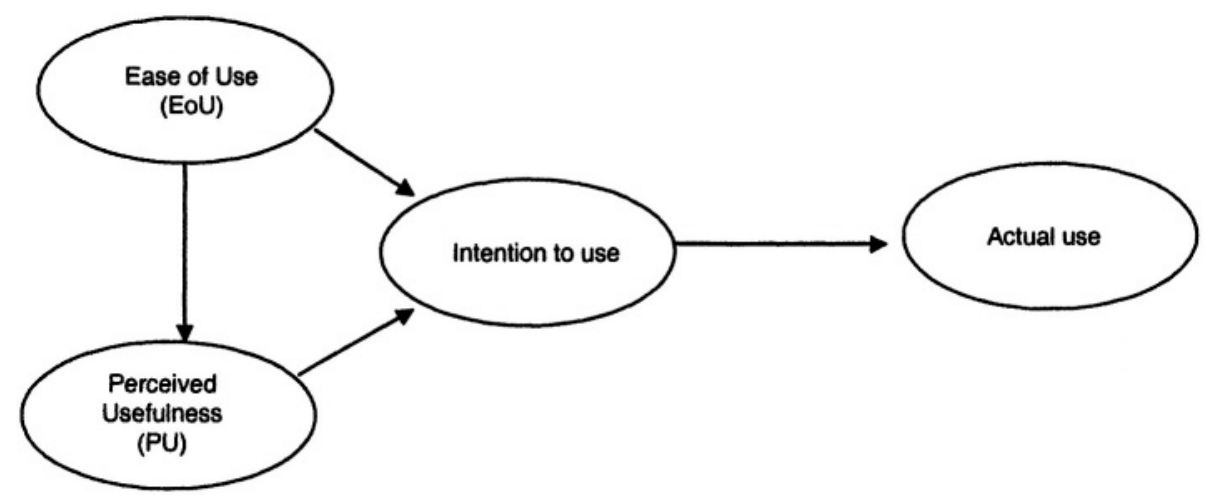

Figure 1. Davis' Technology Acceptance Model (TAM), (Davis, 1989)

The TAM-model has been used in a range of studies. Kwon and Chidambaram (2000) use and test the TAM model to examine patterns of cellular phone adoption and usage in an urban setting. The results of the study confirm that users' perceptions and especially perceived EoU, are significantly associated with the motivation to use cellular phones. Lederer et al. (2000) applies TAM in relation to work-related tasks in the context of the World Wide Web. They find full support for the TAM model and demonstrate that ease of understanding and ease of finding predict EoU, and that information quality predicts usefulness for revisited sites. Yager (1999) uses the TAM constructs to address the perceptions of currently available and yet-to-be-released IT support mechanisms among virtual and face-toface (non-virtual) teams. The study shows that virtual team members reported greater EoU and PU of the IT support mechanisms than non-virtual team members together with more Intention-to-use. Pavlou (2001) extends the TAM model to incorporate the constructs of risk and trust in consumer intention to adopt electronic commerce. The TAM model has also been extended with variables such as control, intrinsic motivation and emotion (Venkatesh, 2000), and has been used in the marketing field to explain online consumer behavior (e.g. Koufaris, 2002). Social influence has been found important in technology acceptance. Venkatesh and Davis (2000) develop and test a modified version of the original TAM, which explains PU and usage intentions in terms of social influence (subjective norm, voluntariness, and image) and cognitive instrumental processes (job relevance, output quality, and result demonstrability). This study was however not done in concern to virtual teams or Groupware technology.

Originally the TAM-model was developed to study the integration and acceptance of an IT-system in an individual setting, and the different constructs of the model were measured at a given point in time by using quantitative data collected mainly through surveys. Three main points 
differentiate earlier use of TAM from the use in this paper. First our goal is not to measure the TAM's constructs at a given point in time, but instead we want to describe how the different constructs of the TAM-model change during the integration and acceptance process. Secondly we use the TAMmodel in a qualitative study, whereas it is normally used in a quantitative fashion. Others have also used the TAM-model in a qualitative approach e.g. Neville and Fitzgerald (2002). Finally, while the TAM-model is typically concerned with an individual's acceptance of technology, we use it to investigate a group's acceptance of technology.

\subsection{Virtual Teams and Social Awareness}

Research on the integration of technology in virtual teams is important, because virtual teams in general have more malleable structures due to the typically 'not-yet-organized' and more informal organization (Majchrzak et al. 2000). In this way we can learn from virtual teams when interested in change management. Also research on virtual team is important to understand and support the practice of global organizations. Some research has taken up the challenge of investigating virtual teams by focusing on managerial aspects such as the role of the project manager (e.g. Kayworth and Leidner, 2002; Paré and Dubé, 1999; Piccoli and Ives, 2000), while other research has taken an empirical approach to exploring the process of virtual teams (e.g. Maznevski and Chudoba, 2000). Most of the research has however been conducted with emphasis on special aspect of virtual teams such as culture or trust (e.g. Jarvenpaa et al., 1998; Massey et al., 2001; Alexander, 2002). No research has however addressed the importance of social perspective awareness in virtual teams.

Social and people-centered issues such as social awareness have been found important when researching group collaboration (Steinfield et al., 1999; Prinz, 1999, Tollman et al., 1996; Schmidt, 2002). Awareness as a concept has been categorized in different ways. Prinz (1999) identifies two types of awareness: social awareness and task-oriented awareness. In our study the type of awareness relevant to the integration of Groupware can be categorized as social awareness according to Prinz (1999: p. 2) definition: namely, to provide information similar to 'information received when walking along the office floor'. Others have also located the importance of social awareness saying that "Awareness involves knowing who is "around", what activities are occurring, who is talking with whom; it provides a view of one another in the daily work environments (Dourish and Bly, 1992)".

Steinfield et al. (1999) proposes a number of awareness categories, including activity awareness, availability awareness, process awareness, environmental awareness, and perspective awareness. A full discussion of 
each of these categories is beyond the scope of this paper. However, the one most relevant to our study is that of perspective awareness which is defined as 'giving group members information helpful for making sense of others' actions, such as background on team members belief and knowledge' (Steinfield et al., 1999: p. 84). There is a difference between knowing who is around and background knowledge necessary to interpret others' actions. In our empirical data, the importance and need was on the background knowledge: perspective awareness.

For the purpose of this study, we complement therefore Prinz definition of social awareness with aspects of perspective awareness in giving group members information helpful for making sense of each others' actions so that the information received is similar to the one gathered when walking along the office floor'. Finally, the setting investigated in our study is an asynchronous setting, meaning that the team members do not work synchronously or at the same time, while being apart from each other. The need for 'knowing if people are available in a synchronous perspective' is thus not an issue. Therefore, our concept of social awareness differs, from Tollmar et al. (1996) and Dourish and Bly (1992), which both focuses on a synchronous context. The awareness concept used in this paper can be defined as asynchronous social perspective awareness - here just referred to as social awareness.

\section{THE RESEARCH CONTEXT}

\section{1 $\quad$ Research setting}

The empirical investigation was conducted within a part-time Master program (the Master of Adult Education at Roskilde University in Denmark), where a virtual learning team was closely followed. The focus of the investigation was to facilitate and in this way locate important factors for success when integrating the Groupware technology BSCW in the virtual team.

The master of adult education is a three-year part-time university education for people active on the labour marked. To apply and being accepted the students need a bachelor degree and at least two years of job experience. The average participant is a woman between 40 and 50 years old working with health or education in the public sector. Because it is a parttime education each semester is stretched over a whole year from September to June, and each year the program requires the students to attend five weekend-long seminars on campus in September, November, January, 
March and April. Over 50\% of the program is based on project work in groups of two to four participants with an academic supervisor.

The team in focus consisted of three students in their mid-thirties: Emma, Thomas and Lisa. They all had families and were in full-time employment, so study-time was on weekends and evenings. The three team-members lived far apart, leaving little opportunity to physically meet, apart from the five seminars on campus. Due to different working hours the team primarily collaborated asynchronously. On this basis, we classify the group as a virtual team according to Steinfield et al. (1999) definition: 'any group characterized by having members in different locations' and use the terms virtual learning team and group interchangeably.

It could be argued that there is a difference between groups in educational and working contexts. However, following the Schmidt and Simone' (1996: p. 158) definition of cooperative work as 'constituted by the interdependencies of multiple actors who interact through changing the state of a common field of work', we believe the setting of the study represented a true and realistic work context. The multiple actors were Emma, Thomas and Lisa, the common field of work was their project, and the state was changed through discussion, reading, writing, revising documents - which in the end led to the final project report they turned in to the exam.

Our research focused on the coordination activities surrounding the production of an outline of a project report that the group was required to submit to the supervisor by a particular deadline. The research was conducted during the group's last year at the university. All group members had experience with project work in virtual teams mediated by e-mail and phone, but no experience in using Groupware to support their collaboration.

\subsection{Technology}

The Groupware system used in the investigation was Basic Support for Cooperative Work (BSCW, further details at bscw.gmd.de), one of the most well known CSCW (Computer-Supported Cooperative Work) systems in the academic world (Bentley et al., 1997).

The BSCW system is a web-based CSCW system, which supports filemanagement, asynchronous and synchronous dialogs, management of URLs, and calendar functions. The BSCW system also supports different awareness functions such as monitoring which documents, folders and notes are new, read, revised or moved. It is also possible to get automatically e-mail notifications, when different events occur within the system. The BSCW broad functionality and versatility, which allow users to adjust the conceptual structures as needed makes it a strong tool, when there is a 
requirement to collaborate and coordinate different tasks within a distributed group.

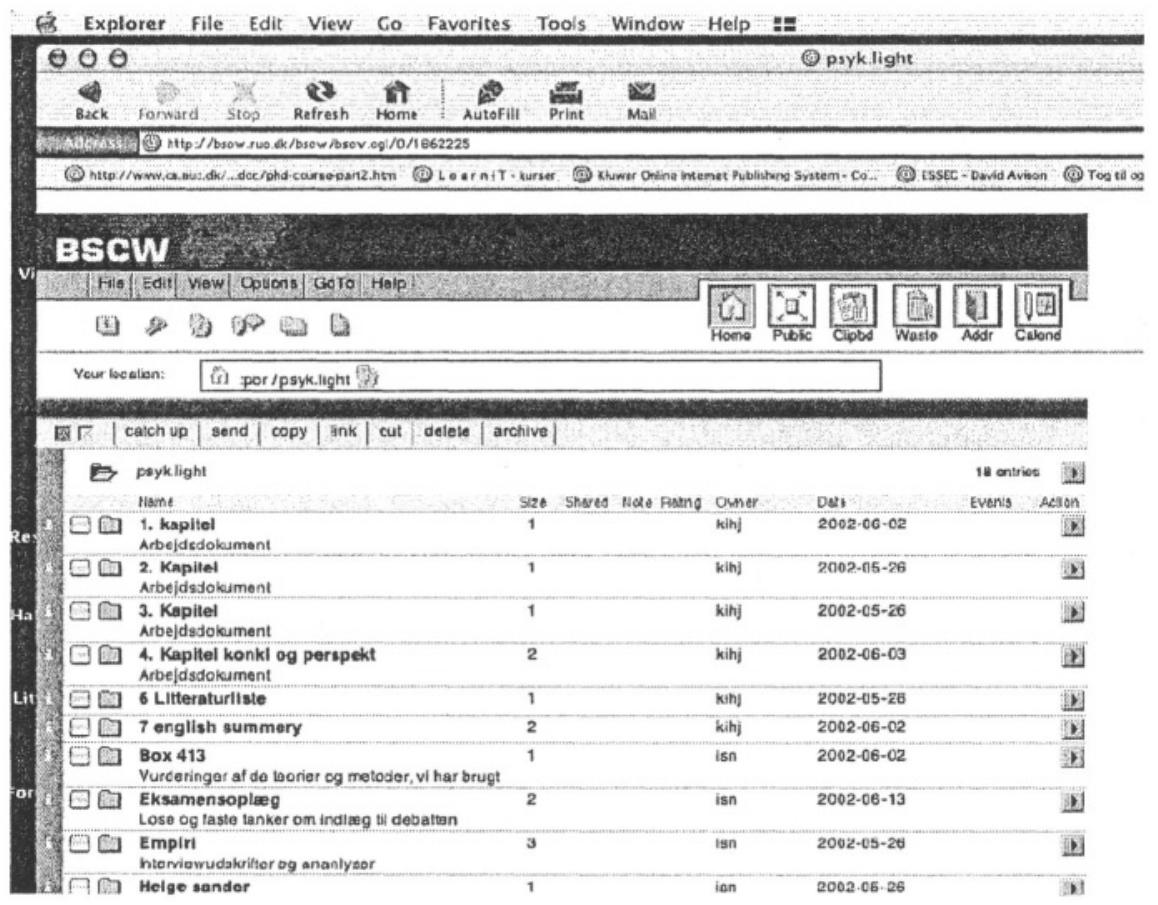

\subsection{Research method}

Research on Groupware integration and use based on 'experimental settings' with the sole purpose of evaluating Groupware has produced confusing and inconsistent results, because it is not possible to simulate reallife collaboration (Davison et al., 1998). Davison et al. (1998) proposes, instead, using action research to fully capture the complexity of Groupware use and collaboration. Using the action research approach in the Information Systems (IS) community is well known (e.g. Mathiassen 1998, 2002; Avison, Lau, Myers \& Nielsen 1999; Vidgen and Braa, 1997; Braa and Vidgen, 2000; Donnellan, 2003). The IS action research approach combines theory and practice through change and reflection in a problematic real-life situation.

The triangle in Fig. 2 represents the unity of the three goals: to understand, to support and to improve. The arrows inside the triangle represent the distinct research activities through which the different goals are supported. Having the activities inside the triangle illustrates that each 
activity can benefit from the other activities. "First, our understanding is based on interpretations of practice. Second, to support practice we simplify and generalize these interpretations and engage in design of normative propositions or artifacts, e.g. guidelines, standards, methods, techniques, and tools. Third, we change and improve practices through different forms of social and technical intervention." (Mathiassen, 1998: p. 20). In this way different studies are placed in different locations of the triangle.

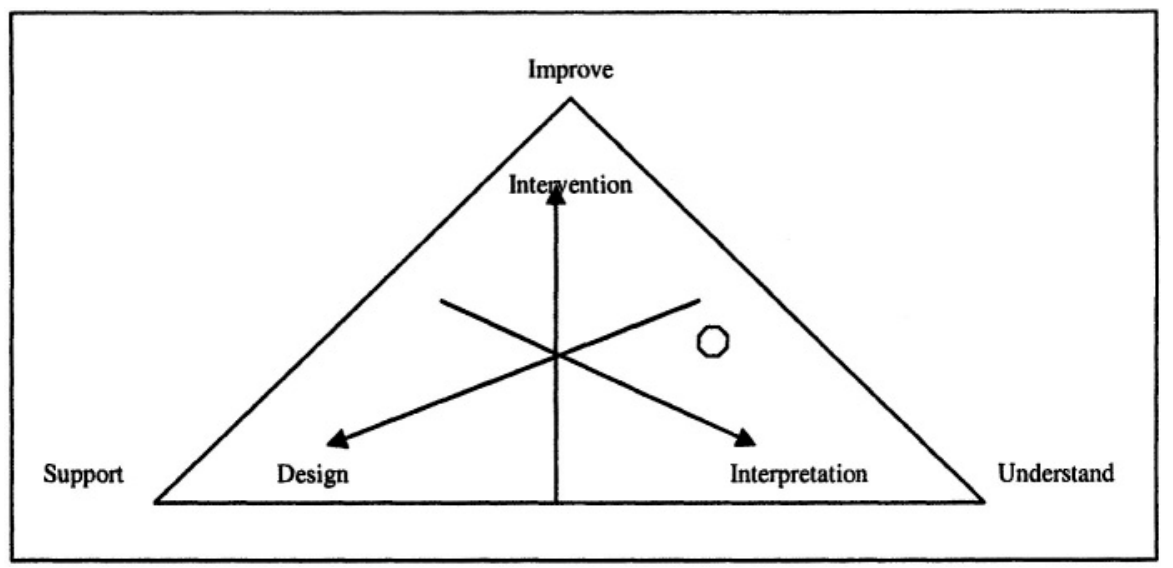

Figure 2. A Framework for Action Research (adapted from Mathiassen, 1998)

The study presented here was lead by the research question: What are the factors influencing the integration process of Groupware technology in virtual learning teams in part-time adult education? In pursuing this question we wanted to understand practice (the social practice and collaboration within virtual learning team) with the aim of supporting the practice (support of coordination and social aspect by Groupware) and then intervene with the practice (facilitate the integration of Groupware to support the group's needs). As predicted by the research question our emphasis is on the understanding of the practice in the virtual team (what are the factors...) in combination with a motivation for facilitating and improving the integration process. In this way we position ourselves in the triangle as closer to improve and understand than to support (see circle in fig. 2).

When doing action research it is crucial to be explicit about the role of the researcher. The role of the researcher in this study was to act as an outside facilitator and process-supervisor in the integration of Groupware in the virtual learning team. It was made explicit to the students that the integration of Groupware should support their collaboration, and if they did not find the Groupware useful they should state this. This approach made the students to be critical towards the technology. As a result, they clearly stated throughout the investigation if and when they were unhappy with the 
technology and what they would have liked to change. The researcher had no direct connection to the Master of Adult Education program, and was not one of the teachers within the Master education.

\subsection{Research activities}

The research took place over the period September 2001 to June 2002. In September the research project was presented to all the students attending the first on-campus seminar in the third year, and the students were asked if they were interested in participating. It was made clear to the students that the researcher not only wanted to make the technology available to the students, but also wanted to facilitate the use being a process-supervisor. The work of the researcher was then supporting the team in both the technical functions and in translating the teams work patterns into guidelines for adjusting the conceptual structures in BSCW. One team volunteered to participate to the research project.

During the whole research period, four intervention points in the process were analyzed: November 2001, January, March and April 2002. In November 2001 a workshop of six hours was held. The workshop activities were recorded for later analysis by using wall-graphs (Simonsen and Kensing, 1997) and tape-recording, in addition to a personal logbook written by the researcher just after the session. In January 2003 the researcher's intervention took the form of a focus group interview (Kvale, 1996). The interview lasted about 2 hours, was tape-recorded for later analysis combined with wall-graphs and rich-pictures (Checkland and Scholes, 1990).

The third researcher's intervention was another evaluation session held in March 2002. The researcher was not present due to external reasons. The team was, therefore, given a list of questions to discuss. The questions could be divided into two types. One type related to the evolution of the project itself and another aiming at finding out the role of BSCW in the collaboration. Examples of questions are: Which kind of document do you have at this time? How far are these? And are there documents not placed in BSCW? Try to describe what you have been doing in the past period and how BSCW or other kinds of technology (like phone and e-mail) have worked? The team recorded the conversation, and these data were later analyzed by the researchers. The researcher asked the team some clarifying questions through the BSCW system after listening to the tapes.

The last intervention in April was organized as one-hour focus group interview. The session was recorded on tape for later analysis. In between the different intervention sessions the researcher had observed and recorded the group's activities within BSCW and intervened if necessary or asked by 
the students. This recording was done in the personal logbook held by the researcher.

\subsection{Data analysis}

Each physical intervention with the team was tape-recorded and transcribed within 24 hours in a sequential order to ensure reliability of the data (Perakyla, 1997). Wall-graphs or rich-pictures were made during the sessions, containing rich-pictures and notes of the sessions. After each encounter two resumes of the session were made. One was done by the researcher and one was done by the team. The collected data were analyzed intuitively by the authors according to the theme of Groupware integration. The parts of the interview text relevant to this theme were then contextualized to the framework of the TAM-model and social awareness (Creswell, 1998; Walcott, 1994). The resumes and conclusions were presented to and discussed with the team in a following intervention session to ensure validity (Creswell, 1998).

\section{ANALYSIS OF THE INTEGRATION PROCESS OF THE BSCW GROUPWARE SYSTEM}

In this section we use the TAM-model to analyze and describe the evolution of the integration process of BSCW in the virtual learning team over the four points in time described above - November, December, January and March. The analysis illustrates how BSCW was adopted and accepted by the virtual learning team, and how BSCW contributed to reduce coordination efforts, achieve a mutual understanding of each other and support collaboration, thus indirectly supporting also social perspective awareness among the members of the team.

\subsection{November setting}

Due to the geographic distance among Emma, Thomas and Lisa, the first workshop between the researcher and the team was conducted on a Friday evening between 6:00pm and midnight the day before a Master seminar on campus. The purpose of the workshop was for the researcher to support the team in the negotiation of both the content and the goal of the project, and to find out how the team could use the BSCW to support their collaboration.

The team negotiated the project and developed a first common understanding for the use of BSCW to support collaboration. The 
understanding was based on the team's earlier experience with project work, combined with examples of how to use BSCW efficiently to support the task at hand. This was then used to design the conceptual structures of BSCW e.g. which folders should be created, how they should be named, and more importantly, how the participants should use the different folders. The result of the November activity was a project contract mainly describing the overall plan for the project, and a designed BSCW workspace. The researcher also held a hands-on introduction to BSCW technical functionalities. When asked to reflect on how the distributed collaboration was perceived after this November workshop, a group member expressed it as follows:

"I think we all had a feeling of being far more on track than the year before. It was a relief to have an overview of the project and process even though it might have been an illusion. (...) the hard thing about this parttime education is that you sometime lose feeling with the project and then something like this (BSCW) is extremely good to have." (Group member in January 2002)

Thus, the November introductory session on how the group could use the BSCW system to coordinate the work did induce a feeling that the BSCW system would be useful in supporting collaboration. In TAM's terms, the perceived usefulness (PU) was positive (depicted as + in Fig. 3). The group had gone through the different functions and constructed the folders agreed upon, however the question of how easy it was to use did not arise as an issue. Thus, the group's view on the EoU construct was 'missing' or neutral at this point in time (depicted as 0 in Fig. 3). Still the high PU made the Intention-to-use high, and the expectation of Actual-use was high. However, we did not know at that time whether the group would actually use the Groupware in the future (depicted as ? in Fig. 3).

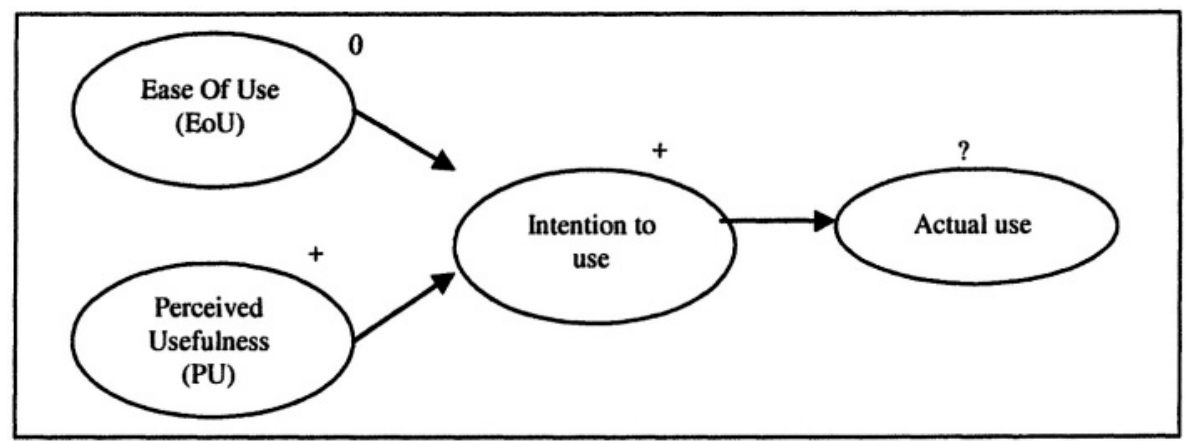

Figure 3. November setting; BSCW use in TAM. 


\subsection{December setting}

The period from November to December was characterized by very low or almost no interaction within the group. Due to the members' daily work and family routine, the group did not have any kind of collaboration in this period. The members did logon to BSCW to 'see' if anything was happening and there were one or two small discussion-notes added but none were answered. Then between Christmas and New Year the group held a telephone-conference to "start up the communication again", as they put it. The main issue for the telephone meeting was to discuss and coordinate the production of an outline of the project to be sent to their supervisor before meeting him in January. In the telephone discussion about how to proceed to coordinate the document they decided not to use BSCW, but e-mail and telephone instead. When asked in January why they had decided not to use BSCW, a group member explained:

"The thing with the BSCW is that when the working process is not continuous (...) then nothing happens (...) so it becomes like a stranger out there"

(Group member in January)

In a part-time education program, where the participants use their free time to study, the process will never be continuous, and this makes it difficult to achieve sustained use of the Groupware technology. Analyzing the situation in December using the TAM model, the main issue emerging was the EoU (Fig. 4).

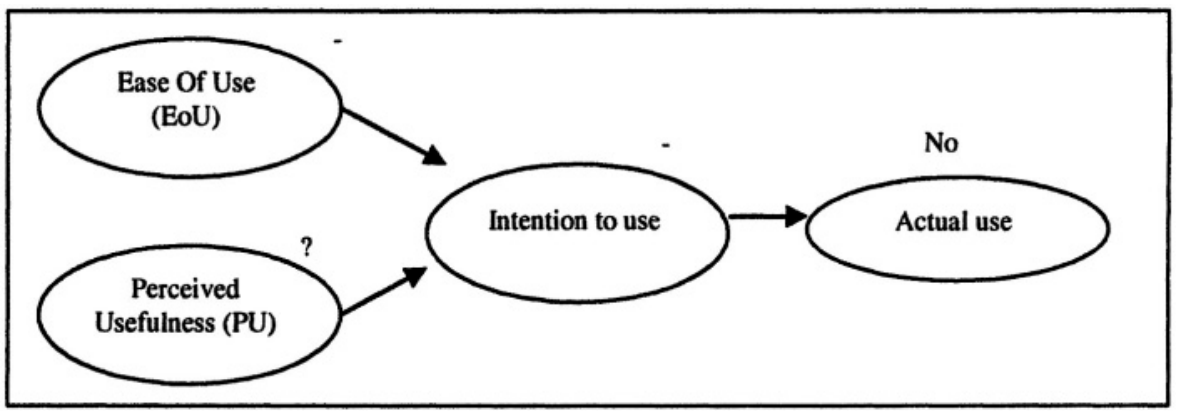

Figure 4. December setting: BSCW in TAM.

The high expectations and Intention-to-use BSCW present in November decreased in December because the focus in this period shifted from learning how to use the technology to creating the content and coordinating the project outline to be delivered to the supervisor. The perception that BSCW would be useful in the coordination process began to be questioned (depicted 
by ? in Fig. 4). The group started to question whether BSCW actually could help them reduce the complexity of coordination, and as the EoU factor started to be problematic (depicted by - in Fig. 4), the Intention-to-use was also reduced. The result was that the group did not actually use the groupware technology between November and December, but instead chose to rely on the more familiar e-mail and telephone. When we model the use of e-mail and telephone technology using the TAM model, the scenario in Figure. 5 emerges.

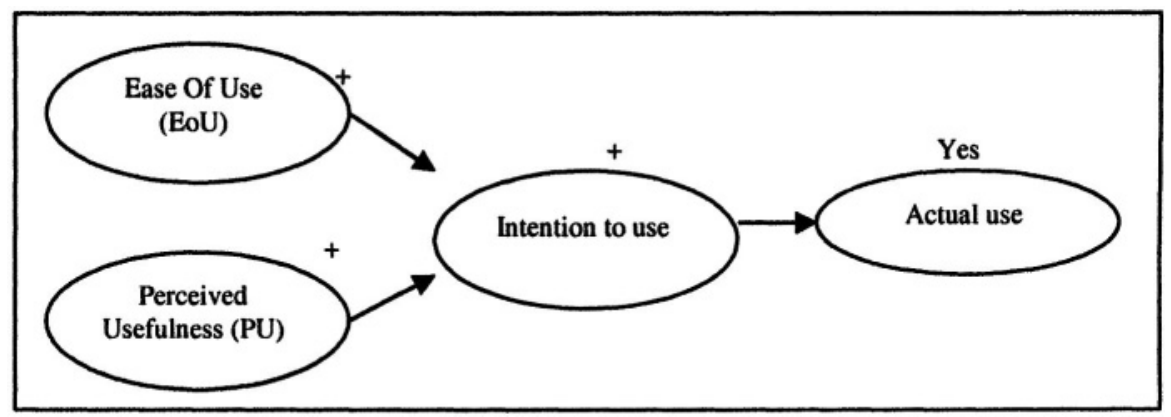

Figure 5. December setting: e-mail/telephone in TAM

The EoU concerning e-mail and telephone was positive. They were both familiar technologies and used previously by the group for coordination purposes. At the same time the expectations that these familiar technologies would support coordination were high due to earlier experience. So both the PU and Intention-to-use were high, leading to the Actual-use of e-mail and telephone to coordinate the production of the project outline. Thus, the Actual-use of these technologies was achieved.

\subsection{January setting}

In January a new workshop was held to evaluate the use of the Groupware system in the period from November to January. Here the group was encouraged to articulate the actual collaboration process as experienced from November to January. Knowing they had used e-mail and telephone to coordinate the outline, the main question was whether these "more traditional" technologies were successful in coordinating the document production. If they were, then the inevitable question would arise as to the need for the Groupware system. However, it transpired that the use of e-mail and telephone to support the project coordination had failed. The group did not actually realize this before the January meeting with their supervisor to whom they had already sent the document by e-mail two days before. They thought they had a common understanding of the content and the process by 
which the document had been produced, but it was not the case. The following discussion went on in the workshop:

Thomas: I think there is something missing here on the first few pages [pointing at a printed version of the document].

Emma: Is this not the last version you sent?

Thomas: No it is not.

Emma: The one you sent a couple of days ago?

Thomas: The one we mailed to Adam [the supervisor], the one we called version 4, the one Lisa had written on - unfortunately I don't have a printed version because my printer isn't working, but Lisa had put mine and hers together; it is about 6-7 pages long...(...)

(Group discussion, January)

This discussion continued and they got more and more frustrated about the situation. They did not have a printed last version, and at the end they decided to contact the supervisor to check if he had gotten the right version. They also started discussing the e-mail coordination process, and soon realized that they did not have a common understanding of the process underpinning the situation:

Emma: No I just had a thought, if I did get that e-mail I would have made a printed copy and taken it with me.

Thomas: Well, have you then got it or what? Sometimes I have trouble with my e-mail (...)"

(Group discussion in January)

By examining the situation using the TAM model, it becomes clear that the group had been incorrect in their December expectation regarding the perceived usefulness of using e-mail and telephone for coordinating the project outline and submission. The group now realized that the e-mail and telephone technology had not been adequate. 


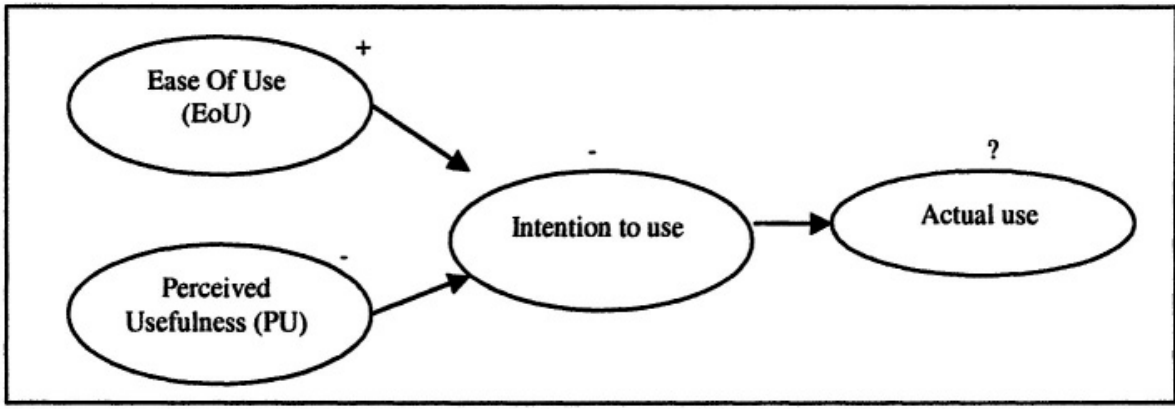

Figure 6. January setting: e-mail/telephone in TAM

As shown in Fig. 6, in January the PU of e-mail and telephone has been altered from positive to negative. The EoU was not changed, but the low PU affected the Intentional-use of e-mail for this kind of task. The low Intention-to-use made the Actual-use less likely. This experience affected, in turn, the use of BSCW. The PU of BSCW was restored also due to the need for 'something else.' Also, at the end of the workshop in January, a number of specific actions were taken by the researcher to help improve the EoU of the BSCW system. These actions were: 1) a new hands-on introductory session, 2) a written description of the functionalities of the BSCW system, 3) writing up three scenarios on how to use the BSCW for coordination, 4) turning on the BSCW direct notification function which would alert group members of relevant events occurring in the system, 5) setting up a discussion forum called weekly logbook, where group members could write comments about the project, together with personal information and other issues they wished to mention.

All these actions were meant to help the group overcome the troubles they had experienced using BSCW (low EoU). The PU for the BSCW system was high due to the coordination difficulties experienced with e-mail and telephone earlier. The EoU was also high as a consequence of the new training on the BSCW technical aspects. However, the main explanation for the positive increase in EoU was the January introductory hands-on session. One of the group members expressed the EoU this way:

"Now we need to get past these [feelings towards BSCW] and say; ok it is not that difficult and instead realize that this [BSCW] actually makes it easier to get access to each other. I think that what we need is to commit to the system."

(Group member in January)

The expectation for using the BSCW for future coordination was high at the end of the January workshop. However, the group had not actually used BSCW yet. 


\subsection{March setting}

The situation for the group had changed in two ways in March (Fig. 7). Firstly, they had managed to integrate the BSCW in their collaboration. This was clear by the large number of actions in the system, e.g. revising the structure of folders, uploading lots of documents and leaving notes in the weekly logbook. Secondly, the group collaboration had changed; they had developed a common understanding of how the project was taking shape, and also of the process of working on the project. The overall purpose of introducing BSCW was to reduce the effort required for coordination.

The group had managed to coordinate different documents while still keeping track of changes and versions. However, it emerged during the March workshop that the most interesting part of using BSCW was the weekly logbook. The weekly logbook had been originally established to encourage regular use of BSCW in the group to increase the EoU. However reflecting back on the situation in the March meeting, the group realized that they had expressed a need for 'something' not only related to the coordination of documents already in January.

“(...) in the period [November to January] I needed to know how you were doing and so... or up to this seminar, how will we get the things we need to do done... I would have liked that kind of communication." (Group member in January)

The need being expressed here was awareness. In co-located teams the daily small interaction around the coffee-machine or water-cooler helps members to get a sense of each other. Lack of such information in virtual teams can affect group morale due to the possibility of misunderstandings and misinterpretations. When other group members are out-of-sight, this may be misinterpreted as inactive and unproductive. The group expressed a need for awareness related to the task they were doing, but also something more - the need for social awareness. In March a positive side effect of the integration of BSCW emerged. The use of BSCW and more specifically, the use of the weekly logbook had supported the need for social perspective awareness. The Groupware technology had affected the social setting of the virtual team.

Lisa: I think this weekly logbook has been very good, because I have had a good sense of where you all have been especially you Thomas, who have written all about your illness. 
Emma: It makes it much more captivating to go in and read stuff like this too.

Thomas: Yes (...) because it gives you a good feeling of what is going on. (...) The constant response. It is especially good in these kinds of distance projects.

Lisa: $\quad$ Sometime you get hung up with work and lose contact with the project...

Emma: (...) you know you have it all in BSCW (...) it gives you a sense, psychologically, that there is a project forming."

(Group discussion in March)

The use of the weekly logbook had given the group a sense of awareness both in the task-oriented and social-oriented sense. The logbook content provided extra information e.g. about interviews that had been conducted and about members' health and family situation. The group members pointed out how useful the first was for example in later analysis of the transcriptions. The weekly logbook had been also a useful way to have 'casual social encounters' in an asynchronous way, simultaneously hosting coordination activities such as planning and task location. One example was the cancellation between January and March of a telephone meeting, which had been planned during the workshop in January in favor of BSCW use. When asked why, they explained that it was too expensive. The cost of a telephone meeting had not been an issue between Christmas and New Year because they needed it for coordination, but after BSCW integration in their work, the perceived need for the telephone was reduced.

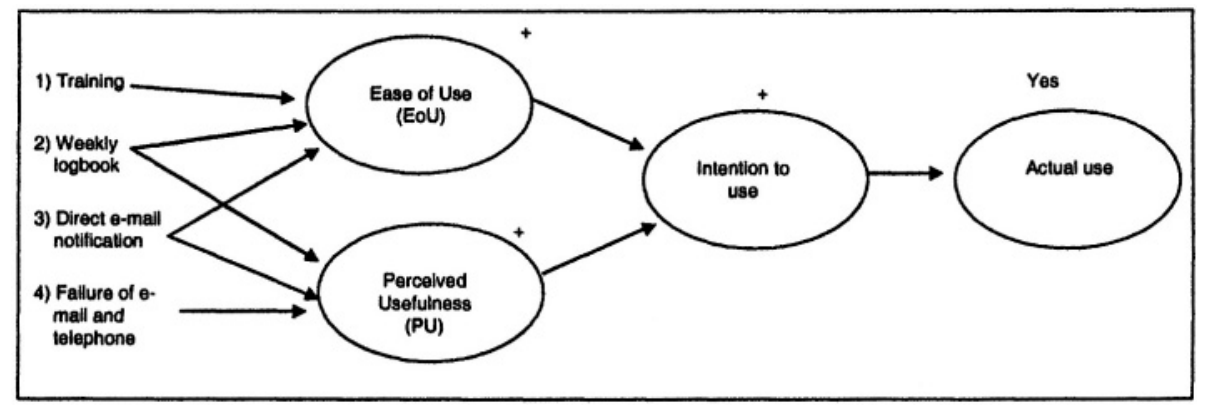

Figure 7. March setting: BSCW in TAM.

The weekly logbook in combination with the direct notification feature supported social awareness, both in an active and a passive manner (Steinfield et al., 1999). The passive manner was due to BSCW direct 
notification feature, turned on in the January workshop. This meant that each time a member wrote, revised or moved objects within the system, an automatic e-mail was sent to all members informing them of the activity. Each member could therefore monitor when others had made a contribution in the weekly logbook. The active way was due to the fact that to actually read the content of the contributions, the members needed to logon to BSCW and actively click on the weekly logbook. As a result the weekly logbook had a huge impact on the EoU, because it caused the participants to use the system functionality regularly.

The weekly logbook facilitated spontaneous and informal interaction by being a free-form discussion forum, with no prescription as to usage or content. Still the participants needed to actively provide the awareness data (writing notes), which requires a deliberate and obtrusive strategy, as opposed to a situation where the data might be automatically generated. This aspect could have caused distraction and the related extra effort might cause resistance and non-acceptance of the technology. This was not the case. If the weekly logbook were perceived as a lot of extra work without relevance, the group would have perceived it as a distraction leading to decreased PU. It was very evident in March, instead, that the group had successfully integrated the BSCW technology to achieve the necessary collaboration.

\section{DISCUSSION}

So, what does our analysis using the TAM-model tell us about the integration process of Groupware in virtual teams in the Master of Adult Education? To summarize, in November we learned that highly PU did have a big impact on the Intentional-use and that the EoU was not even an issue. The data suggest that in the case of Groupware technology, high PU can supercede the importance of EoU, resulting in high Intentional-use. It was however not our goal to test, evaluate or change the TAM-model - and further elaboration in this direction would require more data.

However, we have learned in December that when it comes to the Actualuse, the EoU influence is vital. In fact, the conditions had changed in December due to little interaction and deadline pressure, which made EoU for BSCW more important than in November. This led to no Actual-use of BSCW, but to the use of the more familiar technologies instead: e-mail and telephone. Therefore we can conclude that the influence of both EoU and PU is present and important in the integration of Groupware technology in virtual learning teams.

During the January workshop the conditions for using BSCW to support the collaboration changed dramatically. It had become apparent to the group 
members that the December perceived usefulness of e-mail and telephone had not materialized. Instead, the new initiatives such as training, direct email notification and weekly logbook had increased the EoU and PU of BSCW, even though the initial aim was only to increase EoU. The changed conditions of EoU and PU influenced the Intentional-use, and in March this led to Actual-use of BSCW. We had expected that the weekly logbook would increase only the EoU, instead we found out that the logbook also had increased the PU. Surprisingly the weekly logbook had supported a need for social interaction within the virtual learning team. Due to the large physical distance between the members, the group had a need to know about each other' intentions and actions, not only in relation to work but also in their social life. This need we have identified as social perspective awareness. The social awareness was supported by the weekly logbook within BSCW, and the use of the weekly logbook substantially contributed to BSCWs acceptance by the group. This in turn led to the integration of BSCW in the collaborative practice of the virtual team.

\section{CONCLUSIONS, LIMITATIONS AND SUGGESTIONS FOR FURTHER RESEARCH}

The overall research question in this study was: What are the factors influencing the integration process of Groupware technology in virtual learning teams in part-time adult education? On the basis of an in-depth action research study (Mathiassen, 1998; 2002) conducted in a Problem Oriented Project Pedagogy Master Program at Roskilde University, Denmark, we got rich data describing the integration process of BSCW in a virtual learning team consisting of three students. We used the TAM-model to describe and analyze the data collected in four key checkpoints and found it useful in the description of successes and failures during the integration process of Groupware.

We can conclude that the TAM model can be used in a qualitative way to analyze and interpret technology acceptance. Furthermore in the specific setting of Groupware integration in virtual learning teams, we can conclude that both EoU and PU are important for the Intention-to-use and the Actualuse. We also found that social perspective awareness influenced the PU, which affected the Groupware integration in a positive way. Therefore we can conclude that one important factor influencing the integration process of Groupware technology in part-time adult education is: How the technology can provide support for social perspective awareness, which can in turn influence the PU of the technology. 
The limitation of the study presented in this paper arises mainly in two aspects. Firstly the empirical work was collected with a virtual team consisting of students and thus it is somewhat questionable as to whether social awareness would have the same importance in virtual teams in business environments. However, even though it was not our goal to generalize our findings from an educational setting to a business setting, we expect social perspective awareness to be important within virtual teams in a business context as well, at least in relation to project coordination and document handling. We would propose that future research - qualitative as well as quantitative - should be done in business settings to test our results. The second limitation of the study lies in that, we on the one hand use the TAM-model in a total new setting (groupware, qualitative study, different goal) and on the other hand the study does provide some evidence to question the model's use in this setting (e.g. the causal relation between EoU and PU). Thus, we can conclude that the results of the study do not fully support the model, and this could be used to generate a new and revised TAM-model to be used in this setting. This is however beyond the goal of this paper. Here the main purpose was to use the TAM-model in a descriptive way when investigating the integration process, rather than trying to question its explanatory effect. To conclude we propose to use the TAMmodel in qualitative studies in future research investigating Groupware integration in virtual learning teams. Also, we suggest that such investigation should focus on conditions influencing both EoU and PU in an integrated manner in the search for how to successfully integrate Groupware, and especially explore the role of social awareness in the integration of Groupware technology to support collaboration.

\section{ACKNOWLEDGEMENTS}

This paper is based on an earlier version co-authored by Pernille Bjørn, Brian Fitzgerald and Ada Scupola presented at IRIS 2003 conference in Haikko Manor, Finland. We would like to thank Brian Fitzgerald for reading and commenting on earlier drafts of this paper as well. Finally we also would like to thank the IFIP reviewers for profound and useful comments.

\section{REFERENCES}

Adams, D, Nelson, R. and Todd, P. (1992): Perceived usefulness, perceived ease of use and user acceptance of information technology: a replication, MIS Quarterly, (16, 2), July, 1992, pp. 227-247. 
Alexander, P.M. (2002): Teamwork, Time, Trust and Information, in Proceedings of SAICSIT 2002. pp 65-74.

Avison, David; Francis Lau, Michael Myers and Peter Axel Nielsen: Action Research, in Communication of the ACM, January 1999, Vol. 42, No. 1

Bentley, R. T., T. Horstmann, and J. Trevor: The World Wide Web as enabling technology for CSCW: The case of BSCW, Computer Supported Cooperative Work: The Journal of Computer-Supported Cooperative Work, vol. 6, no. 2-3, Kluwer Academic Publishers, 1997, pp. 111-134

Bjørn, P. (2003): Re-Negotiating Protocols: A Way To Integrate GroupWare in Collaborative Learning Settings, Proceedings of European Conference in Information Systems (ECIS), Naples, 2003.

Bødker, K., Kensing, F. and Simonsen, J. (2003): Professional IT design - the foundation for sustainable IT usage, Forthcoming MIT Press.

Braa, K. and Vidgen, R. (2000): Research - From observation to intervention, Ch. 12 in Planet Internet. K. Braa, C. Sørensen, B. Dahlbom (eds.), Studentlitteratur, Lund, Sweden.

Carstensen, P. and Sørensen, C. (1996): From the social to the systematic: Mechanisms supporting coordination in design, Computer Supported Cooperative Work, The Journal of Collaborative Computing, vol. 5, no. 4, 1996, pp. 387-413.

Checkland, P. and Scholes, J. (1990): Soft Systems Methodology in Action, Chichester, West Sussex, UK, 1990.

Cheesman, Robin og Simon B. Heilesen: Supporting Problem-based Learning in Groups in a Net Enviroment, In Proceedings of the Computer Support for Collaborative Learning (CSCL) 1999 Conference, C. Hoadly \& J. Roschelle (Eds.) Dec. 12-15, Standford University, Palo Alto, California. Mahwah, NJ: Lawrence Erlbaum Associates.

Creswell, J.W. (1998), Qualitative Inquiry and Research Design, Sage Publications.

Davis, F. (1989): Perceived usefulness, perceived ease of use and user acceptance of information technology, MIS Quarterly, (13, 3), September, 1989, pp. 319-340.

Davis, F., Bagozzi, R. and Warshaw, P. (1989) User acceptance of computer technology: comparison of two theoretical models, Management Science, (35, 6), August 1989, pp. 982-1003.

Davison, R., Qureshi, S., Vreede, G-J. d., Vogel, D. and Jones, N.: Group Support Systems through the Lens of Action Research: Cases in Organizations, Journal of Global IT Management, 3, 4, 6-23, 2000.

Dirckinck-Holmfeld, Lone og Elsebeth K. Sorensen: Distributed Computer Supported Collaborative Learning through shared Practice and Social Participation, In Proceedings of the Computer Support for Collaborative Learning (CSCL) 1999 Conference, C. Hoadly \& J. Roschelle (Eds.) Dec. 12-15, Standford University, Palo Alto, California. Mahwah, NJ: Lawrence Erlbaum Associates.

Donnellan, B. (2003) Knowledge Management Systems Implementation to Support New Product Development, Unpublished Phd Dissertation, University of Limerick.

Dourish, Paul and Bly, Sara (1992): Portholes: Supporting Awareness in a Distributed Work Group, In P. Bauersfeld, J. Bennet and G. Lynch (eds.): CHI'92 Conference Proceedings: ACM Conference on human factors in computing systems, 3-7 May 1992, Montercy, California, New York: ACM press. pp. 541-577.

Gefen D., Karahanna, E. and D.W. Straub (2003): Trust and TAM in online shopping: An integrated model, MIS Quarterly 27, No. 1, pp 51-90.

Grinter, R. E. and Eldridge, M. A. (2001): y do tngrs luv 2 txt msg?, In Proceedings of the Seventh European Conference on Computer-Supported Cooperative Work, 16-20 
September 2001, Bonn, Germany, pp. 219-238, Kluwer Academic Publishers, Netherlands, 2001

Grudin, J. (1994): Groupware and social dynamics: Eight challenges for developers, Communication of the ACM, Vol. 37, No. 1, 1994, pp. 92-105

Jarvenpaa, Sirkka L.; Knoll, Kathleen and Leidner, Dorothy E. (1998): Is Anybody Out There? Antecedents of Trust in Global Virtual Teams, Journal of Management Information Systems; Spring 1998; 14, 4; ABI/INFORM Global pg. 29

Karsten, H.: Collaboration and Collaborative Information Technologies: A Review of the Evidens, The DATA BASE for advances in Information Systems, Vol. 30, No. 2, 1999.

Kayworth T. R., and Leidner, D.E. (2002): Leadership Effectiveness in Global Virtual Teams, Journal of Management Information Systems, Winther 2001-2002, Vol. 18, No. 3, pp 740.

Koufaris, M. (2002): Applying the Technology Acceptance Model and Flow Theory to Online Consumer Behavior, Information Systems Research, Vol. 13, No. 2, pp. 205-223.

Kvale, S. (1996): InterViews: An introduction to qualitative research interviewing. Thousand Oaks, Ca.: Sage, 1996.

Kwon, H.S., Chidambaram, L. (2000): A Test of Technology Acceptance Model, The Case of Cellular Telephone Adoption, Proceedings of the $\mathbf{3 3}^{\text {rd }}$ Hawaii International Conference on System Sciences, IEEE Computer Society.

Lederer, A.L., Maupin, D.J., Sena, M.P., Zhuang, Y.( 2000): The Technology Acceptance Model and the World Wide Web, Decision Support Systems, Vol. 29, No. 3, pp. 269-282.

Legris, P., Ingham, J. and Collerette P. (2003): Why do people use information technology? A critical review of the technology acceptance model, Information \& Management 40 (2003), pp 191-204

Majchrazak, A., Rice, D.E., Malhotra, A., King, N.: Technology Adaptation: The case of a Computer-Supported Inter-organizational Virtual Team, MIS Quarterly, Vol. 24, No. 4, pp. 569-600, 2000.

Massey, A.P., Hung, Y.C., Montoya-Weiss, M., and Ramesh, V. (2001): When Culture and Style Aren't About Clothes: Perceptions of Task-Technology "Fit" in Global Virtual Teams, Proceedings of the 2001 - International ACM SIGGROUP Conference on Supporting Group Wokr - vol. 2001.

Mathiassen, Lars: Collaborative Practice Research, in Scandinavian Journal of Information Systems - Vol. 14, 2002; pp. 57-76.

Mathiassen, Lars: Reflective Systems Development, in Scandinavian Journal of Information Systems - Vol. 10, No. 1\&2, 1998; pp. 67-134.

Maznevski, M.L. and Chudoba, K.M. (2000): Bridging Space Over Time: Global Virtual Team Dynamics and Effectiveness, Organization Science, Vol. 11, no. 5, SeptemberOctober 2000, pp. 473-492.

Neville, K. and Fitzgerald, B. (2002): An Innovative Training Model for an Organization Embracing Technology, Journal of IT Education, Vol.1, No. 3.

Olesen, H.S. and Jensen, J.H. (1999): Project Studies - A late modern university reform?, Roskilde University Press, 1999.

Orlikowski, Wanda J.: Learning from NOTES: Organizational Issues in Groupware Implementation, in J. Turner and R. Kraut (eds.): CSCW '92. Proceedings of the Conference on Computer-Supported Cooperative Work, Toronto, Canada, 31. October - 4. November 1992, ACM Press, New York, 1992, pp. 362-369.

Paré, G. and Dubé, L. (1999): Virtual Teams: An exploratory study of key challenges and strategies. Proceedings of the $20^{\text {th }}$ International conference on Information Systems, January 1999. 
Pavlou, P.A. (2001) Consumer Intentions to Adopt Electronic Commerce-Incorporating Trust and Risk in the Technology Acceptance Model, Paper Presented at DIGIT Workshop, December, http://www.mis.temple.edu/digit, accessed the $4^{\text {th }}$ February, 2003.

Perakyla, A. (1997), Reliability and Validity in Research Based on Transcripts, in Qualitative Research, Ed. Silverman D., Sage Publications, pp. 201-220.

Piccoli, G. and Ives, B. (2000): Virtual Teams: Managerial Behavior Control's impact on Team Effectiveness, International Conference on Information Systems. Proceedings of the 21 ICIS, Brisbane, Queensland, Australia, pp. 575-580.

Prinz, W. (1999): NESSIE: An Awareness Environment for Cooperative Settings, GMD-FIT, Germany, Proceedings of the Sixth European conference on Computer supported cooperative work, 1999, Copenhagen, Denmark, Kluwer Academic Publishers Norwell, MA, USA, 1999

Schmidt, K. (2002): The Problem with 'Awareness' - Introductory Remarks on 'Awareness in CSCW', Computer Supported Cooperative Work. The Journal of Collaborative Computing, vol. 11, 2002, pp. 285-298.

Schmidt, K. and Simone, C. (1996): Coordination mechanisms: Towards a conceptual foundation of CSCW system design, Computer Supported Cooperative Work. The Journal of Collaborative Computing, vol. 5, no. 2-3,1996, pp. 155-200

Simonsen, J. and Kensing, F. (1997): Using Ethnography in Contextual design, Communication of the ACM, Volume 40, Issue 7, pp. 82-88.

Steinfield, C., Jang, C. and Pfaff, B. (1999): Supporting Virtual Team Collaboration: The TeamSCOPE System, Group 99, Phoenix Arizona USA, ACM 1999 - 1-58113-065$1 / 99 / 11$

Tollmar, K., Sandor, O., and Schomer, A. (1996): Supporting social awareness @Work: Design and experience, in Proceedings of CSCW '96, Cambridge MA, November 1996, ACM Press, pp. 298-307

Venkatesh, V. (2000): Determinants of Perceived Ease of Use: Integrating Control, Intrinsic Motivation, and Emotion Into The Technology Acceptance Model, Information Systems Research, Vol. 11, Issue 4, p. 342-366.

Venkatesh, V., Davis F. (2000): A Theoretical Extension of The Technology Acceptance Model: Four Longitudinal Field Studies, Management Science, Vol. 46, No. 2, pp. 186205.

Vidgen, R. and Braa, K. (1997): Balancing Interpretation and Intervention in Information System Research: The Action Case Approach. In Lee, A.S., Liebenau, J., and DeGross, J.I. (Eds.) (1997): Information Systems and Qualitative Research, London: Chapman \& Hall.

Walcott, H.F. (1994), Transforming Qualitative Data: Description, Analysis and Interpretation, Thousand Oaks, Sage.

Yager, S.E. (1999): Using Information Technology in a Virtual Work World: Characteristics of Collaborative Workers, SIGCPR '99, New Orleans, LA, USA. Copyright ACM. 